\title{
Nietzsche en la Revista Moderna
}

\section{José Ramón Ruisánchez Serra}

University of Houston, Estados Unidos

\section{Resumen}

En este artículo se exploran las publicaciones de Friedrich Nietzsche y sobre su obra en la Revista Moderna. Esto permite meditar sobre el diálogo entre modernismo y positivismo en México, desde la movilización de un "filósofo-poeta" que enuncia su pensamiento de una manera radicalmente diferente a la comúnmente practicada por la filosofía académica y permite, entonces, desestabilizar muchas de las ideas recibidas de la escuela de Gabino Barreda.

\section{Nietzsche in the Revista Moderna}

\begin{abstract}
This article explores both the tracts by Friedrich Nietzsche and the essays on his work published by Revista Moderna. This allows me to think the dialog between modernismo and positivism in Mexico, through the figure of the "philosopher-poet" that radically changes the way of expounding his thoughts from that of academic philosophy, and thus allows for the destabilization of the received ideas of the school of Gabino Barreda.
\end{abstract}

\section{Nietzsche na Revista Moderna}

\section{Resumo}

Neste artigo são exploradas as publicações de Friedrich Nietzsche bem como questões sobre sua obra na Revista Moderna.Isto permite meditar sobre o diálogo entre o modernismo hispanoamericano e positivismo no México, a partir da mobilização de um "filósofo-poeta" que enuncia seu pensamento de uma maneira radicalmente diferente da comumente praticada pela filosofia acadêmica e permite, portanto, desestabilizar muitas das ideias recebidas da escola de Gabino Barreda.

\section{Palabras clave}

Nietzsche Friedrich Revista Moderna modernismo mexicano Filosofía

Positivismo

\section{Keywords}

Nietzsche, Friedrich Revista Moderna Turn of the century Mexican Literature Continental Philosphy Positivism

\section{Palavras-chave}

Nietzsche, Friedrich Revista Moderna Literatura mexicana fim de século XIX

Filosofia

Positivismo 


\section{Modernismo como ethos y como interior}

Como todos los conceptos, el modernismo se vuelve problemático en cuanto nos acercamos y lo sacamos de su quietud. Su duración crece o decrece. En un reciente artículo se fija entre 1880 y 1920 (Pineda, 2016: 218), pero en ocasiones se desplaza su momento inaugural a 1876, cuando se da en México la condición política de su posibilidad con el ascenso al poder de Porfirio Díaz. Lo mismo sucede con su final: 1916, con la muerte de Darío; 1918 con la publicación de Los heraldos negros de César Vallejo, pero también 1921, año del deceso de Ramón López Velarde -aunque su libro El son del corazón solo se imprime en 1932, cuando ya hacía cuatro años que se había editado el último tomo de la edición de Alfonso Reyes de las Obras completas de Amado Nervo-. Para ese momento Tablada ha abandonado su mayor radicalidad vanguardista e intentado con La feria:poemas mexicanos, que firma en 1926, hacerse de la potencia de López Velarde, a quien Xavier Villaurrutia consagra definitivamente en 1935, con su edición de Poemas escogidos que aparece en la editorial Cultura.

Además de esos saltos hacia adelante o atrás en el tiempo, con cada ola académica aparecen nuevas lecturas del modernismo. Algunos ejemplos recientes e importantes: El proyecto inconcluso de Iván Schulman lo relee tomando en cuenta los estudios poscoloniales; The Inverted Conquest de Alejandro Mejías-López, que lo interpreta desde los estudios trasatlánticos, y Capital Fictions de Erika Beckman que lo hace desde las nuevas activaciones del marxismo.

En mi caso, lo he realizado concentrándome en dos de sus publicaciones fundamentales: Revista Azul (1893-1896) y la Revista Moderna (1898-1903), pensadas desde el trabajo de dos nietzscheanos.Rafael Gutiérrez Girardot, que publicó el importante Nietzschey la filología clásica, y Bolívar Echeverría, cuyos planteamientos sobre la modernidad son todos "genealogías", en el sentido que adquiere este término en la obra de Nietzsche.

Creo que puede pensarse en las dos revistas como interiores en el sentido en que lo planteó Gutiérrez Girardot, siguiendo a Walter Benjamin:

Negación del presente y evasión a otros mundos: estas son las dos características del artista en la moderna sociedad burguesa. Pero ello no significa, como se suele insistir, que el artista huye de la realidad. Por paradójico que parezca, el artista no hace otra cosa que vivir dentro de esa realidad que detesta, la del hombre burgués, que también huye de la realidad y se refugia, como lo observó [en "París, capital del siglo xix" Walter] Benjamin, en su intérieur: "Para el burgués el espacio de vida entra en contraposición por primera vez con el lugar de trabajo. El primero se constituye en el intérieur. La oficina es su complemento. El burgués, quien en la oficina tiene en cuenta la realidad, pide del intérieur que lo distraiga en sus ilusiones. Esta necesidad es tanto más urgente por cuanto no tienen la intención de ampliar sus reflexiones sobre el negocio hacia reflexiones sociales. Reprime las dos en la configuración de un mundo circundante privado. De allí emergen las fantasmagorías del intérieur. Para el burgués, este constituye el universo. En él se reúne la lejanía y el pasado. Su salón es un palco en el teatro del mundo" (2004: 58).

1. A lo largo de estas páginas cito o parafraseo de manera amplia mi capítulo "El ethos modernista", primero porque el libro del que forma parte sigue en proceso editorial en la UNAM y segundo, porque incluso cuando se publique, no resultará fácilmente accesible para los lectores argentinos.
En este sentido, las revistas no deben pensarse como fragmentos de libros que, posteriormente, se destilan de sus páginas, sino en la salud de su impureza, en su mezcla; como negación de la causalidad positivista que predomina en los periódicos. ${ }^{1}$

Aunado a pensar sus interiores, donde se mezclan géneros y firmas, me ha parecido necesario apoyarme en un planteamiento teórico que, para mi sorpresa, no se ha explotado con más intensidad: la reflexión sobre la modernidad a la que Bolívar Echeverría dedicó la mejor parte de su vida intelectual. 
En un repaso mínimo de lo que plantea Echeverría, primero que nada, hay que señalar su ampliación radical de la modernidad, en la que veo su más ambicioso trabajo genealógico. Echeverría detecta ya en el siglo $\mathrm{X}$ la aparición de algunos de sus rasgos esenciales. Esta duración en extremo larga, le permite, crucialmente, desadherir la modernidad del capitalismo como su condición de posibilidad. De hecho, aunque en ciertos aspectos, el capitalismo acelera los procesos de modernización, en la medida que impide la generalización de los avances tecnológicos para preservar las máximas ganancias de quien los posee, actúa como freno a dichos procesos de modernidad plena. Así, debido a que no solo existe como consecuencia del capitalismo, se puede pensar la modernidad desde diferentes negociaciones. Entre ellas, la que Echeverría exploró de manera más profunda fue la del Barroco de Indias, pero dejó indicadas otras. El término que prefiere para estas tensiones y que usa a lo largo de su trayectoria intelectual es ethos:

El concepto de ethos se refiere a una configuración del comportamiento humano destinada a recomponer de modo tal el proceso de realización de una humanidad, que esta adquiera la capacidad de atravesar por una situación histórica que la pone en un peligro radical. Un ethos es así la cristalización de una estrategia de supervivencia inventada espontáneamente por una comunidad; cristalización que se da en la coincidencia entre un conjunto objetivo de usos y costumbres colectivas, por un lado, y un conjunto subjetivo de predisposiciones caracterológicas, sembradas en el individuo singular, por el otro (Echeverría, 2002).

Un momento de peligro, como aquel que obliga a una colectividad a modificar su estar en el mundo, deja su marca en un estilo, que sirve como espejo estético del ethos de la comunidad y, además, conmemora, celebra, recibe y ofrece como posibilidad de goce, y no ya una pura negatividad defensiva sorteando el abismo. sino su positividad sensorial, y desde ahí se produce la apercepción de dicha comunidad de su nuevo hacer(se), de su genio.

Por decirlo de manera muy breve, el modernismo latinoamericano fue el aspecto estético con el que las comunidades urbanas de distintos países de la región (y con frecuencia desde fuera de ésta, piénsese en Martí en Nueva York, pero también en Tablada en el supuesto viaje al Japón, en Nervo y Darío compartiendo casa en París ) experimentaron el ethos moderno en su particularidad latinoamericana. De hecho, su aparición marca el momento en que un ethos más amplio, que Echeverría esboza como el ethos romántico - para el que"la vida moderna y su mundo son creaciones del sujeto humano $[\mathrm{y}]$ como tales pueden ser rehechos y transformados en cualquier momento" (2002)-, se desplaza, aproximándose al ethos realista - que reconoce el capitalismo como el mejor destino posible-, creando un territorio híbrido e inédito: se acepta el capitalismo, pero también la posibilidad de crear interiores ricos y complejos en los que la ambición unidireccional capitalista, su utilitarismo, el positivismo como su credo se suspenden;interiores cuya importancia fundamental radica en que son espacios donde los ideologemas capitalistas se puedan discutir y no solo aceptar. ${ }^{2}$ Como he dicho anteriormente y lo repito, dos de estos interiores, cruciales para el Porfiriato, fueron la Revista Azul y la Revista Moderna. En este artículo me ocupo de esta última no solo desde un marco que al final es nietzscheano, en la medida que permite reanalizar una verdad recibida, sino como el primer lugar donde se publicó y discutió a Nietzsche con alguna extensión en México.

\section{Nietzsche, modernista}

¿Cuál es el lugar de la filosofía en estas casas soñadas? ¿Qué filosofía cabe en ellas? ¿Qué filosofía sabe dejar de ser aparatosa, desembarazarse del "sistema" que le garantiza totalidad? Una respuesta importante aparece de manera relativamente temprana,
2. Aunque no es éste el espacio para discutirlo con la amplitud que el tema merece, hay que señalar que, como no escapará a los lectores de Bolívar Echeverría, este tipo de suspensión no queda lejos de la que efectúa el ya mencionado ethos barroco.Por ello, también, hay una cierta afinidad entre las estéticas modernista y del barroco de Indias, que rescata de manera brillante, como síntesis, el neobarroco (piénsese no sólo en la relectura de Martí en Lezama, sino de igual forma en la reciente recuperación de Herrera y Reissig por la escuela neobarroca del Río de la Plata). 
3. Hay una edición del 2008 del libro de Brandes, Nietzsche: un ensayo sobre el radicalismo aristocrático, publicado por Sexto Piso
4. Aunque este no es el espacio para desarrollar la recepción de Nietzsche en México después de estas primeras publicaciones, sí resulta muy importante señalar que, para la siguiente generación, la del Ateneo de la Juventud, sus obras fundamentales son ya las unitarias, leídas en un volumen, y no en publicaciones periódicas. El artículo reciente de Ugalde Quintana presenta un inmejorable panorama de la lectura no sólo de Reyes, sino Sierra, Caso, Vasconcelos y Henríquez Ureña. Sobre la lectura específicamente filosófica, que en este momento aún está por producirse, ver Pereda y Leyva. Sobre Nietzsche en España, el texto fundamental sigue siendo Sobejano. en 1894, cuando Rubén Darío publica en La Nación un artículo dedicado a dos filósofos "finiseculares": el hoy completamente olvidado Multatuli y Friedrich Nietzsche. Este texto - que no forma parte del volumen Los raros (1896), a pesar de que se escribe como parte de esa serie- resulta importante por varios motivos. Primero, porque Darío arranca desde la anécdota local, sudamericana:

No hace muchos meses vivía aún en el Paraguay una señora alemana que, después de permanecer en la república vecina ocho años consecutivos, partió para el país de su nacimiento con objeto de emprender una obra de gran resonancia, esa señora se llama Elisabeth Forster-Nietzsche, y es hermana de Federico Nietzsche, el artista filósofo que reciente y simultáneamente penetró al templo de la Fama universal y a una casa de locos (2016: 267).

Se cruza el Atlántico, pero no de Europa hacia América sino en sentido contrario, para llegar desde aquí a Nietzsche, tal vez más célebre debido a su ocaso desventurado, a su descenso a la locura, pues aún no ha muerto. Naturalmente, aparece el poderoso flujo inverso, de allá hacia acá: Darío lee al filósofo alemán, como lo hará todo mundo, desde Henri Albert hasta Georg Brandes. ${ }^{3}$ Este texto, sin embargo, me deja pensar cómo y, sobre todo, contra qué se lee a Nietzsche desde aquí. Aquí es el espacio que, por primera vez, han vuelto no solo verdaderamente común, sino también más simultáneo los grandes diarios - además de La Nación y El Imparcial en México-y la dicción de autores que se leen en Nueva York, La Habana y Bogotá-Martí, Tablada, Lugones, además del propio Darío-, pero que, de igual modo, como demostró Leopoldo Zea, es una colección de países pedagógicamente similares debido al triunfo del positivismo; triunfo que consiste en dejar de ser casi de inmediato filosofía para devenir pedagogía y, de ese modo, volverse transparente, naturalizarse.

Nietzsche inquietará y arderá contra el fondo supuestamente neutro del positivismo. Darío juzga que "su filosofía es brumosa, y [Nietzsche] reconoce la relativa oscuridad de su obra: [...] la causa de esa oscuridad consiste en la «desconfianza de la dialéctica y aun de las causas»" (2016: 268). El poeta no sabe pensar esta contribución de Nietzsche, sin embargo, su intuición es exacta: la desconstrucción del causalismo recibido, hace de este pensamiento un veneno para el método único del positivismo.

Hay algo más que Darío no explica, pero que al llamarlo "artista-filósofo" implica: la unidad de muchos de sus trabajos es interna, lograda a fuerza de estilo. Y esto le permite sortear la necesidad de coherencia del libro. Estos textos, con frecuencia tan breves que no es abusivo llamarlos aforismos, siempre son menores a un ensayo y se agrupan en cuadernillos temáticos; pero incluso en estas unidades, rehúyen la sistematicidad e invitan a la continua reconfiguración de sus constelaciones. En otras palabras, son ya, desde su redacción inicial, los objetos dispares que alivian al interior de "realidad" y, por lo tanto, permiten el acceso "a otros mundos", como señala Gutiérrez Girardot -pero no solamente como evasión, sino como surgimiento de puntos de vista críticos, desde los cuales es posible repensar esos mundos. Además, claro, estas unidades textuales - el fragmento, el cuadernillo- permiten su entrada en las revistas: no es necesario publicar un libro completo - y es por ello que, en esta primera época, las obras fragmentarias tienen mayor fortuna que su Zaratustra o su Nacimiento de la tragedia. ${ }^{4}$

\section{Nietzsche en la Revista Moderna: sus textos}

La primera aparición de Nietzsche en la Revista Moderna se da un año antes de su muerte, en el número de octubre de 1899 . Se publica una generosa serie de fragmentos de Humano, demasiado humano, sin crédito de traducción, seguramente vertidas del 
francés, como lo muestran ciertas muletillas y vacilaciones (potencia por poder: pouvoir). La selección está dedicada a meditaciones centradas en el quehacer del artista, fundamentalmente del escritor y del músico, lo cual refuerza la fórmula de Darío: el artista-filósofo. La colección abre con un fragmento notable:

Lo perfecto supónese no alcanzado. Estamos acostumbrados, en presencia de toda cosa perfecta, a descuidar la cuestión de su formación, pero a gozar del presente, cual si hubiera surgido del suelo por arte de encantamiento. [...] El artista sabe que su obra no alcanzará a su efecto pleno sino cuando despierte la creencia de una improvisación, de una milagrosa espontaneidad de producción y favorece así la ilusión e introduce en el arte elementos de inquietud entusiasta, de desorden que aprovecha ciegamente, de ensueño que cesa al comenzar la reacción, cual un medio de engaño, con tal de disponer del alma del espectador o del oyente de manera que crea en el repentino surgir de lo perfecto. La ciencia del arte debe, según va de sí, contradecir de manera expresa dicha ilusión, y demostrar las deducciones erróneas y los malos hábitos de la inteligencia, gracias a la cuales cae en las redes del artista (Nietzsche, 1899: 300).

Sarah Kofman ha llamado la atención sobre este pasaje, para reflexionar sobre lo que denomina "el olvido de la metáfora"; este olvido, a semejanza del que produce lo "perfecto", no es una erosión que se vaya produciendo, sino que "El olvido de la metáfora no sucede en algún momento específico - después de cierto tiempo-y no se aplica solo con respecto y debido al concepto. Es originario, el correlato necesario de la actividad metafórica misma" (1993: 25; la traducción es mía). Tal borramiento instantáneo es, acaso, la mayor dificultad para iniciar el trabajo de la genealogía, eso que, efectivamente, volverá "brumoso" lo que antes era transparente y permitirá el cuestionamiento del statu quo político de la "Pax Porfiriana" y de su pedagogía positivista - que, como toda ideología se pretende "perfecta".

Como sucede con las constelaciones de fragmentos de Nietzsche, esta dificultad, la del olvido instantáneo de que lo perfecto ha sido formado con trabajo, mediante un proceso, ofrece una posibilidad de superarse más adelante:

De qué manera da belleza el metro. El metro coloca un crespón sobre la realidad; da lugar a algún artificio de lenguaje, a alguna indecisión de pensamiento: por la sombra que arroja sobre las ideas tan luego oculta, tan luego hace resaltar. Así como es necesaria la sombra para embellecer, lo "sombrío" es necesario para aclarar. El arte vuelve soportable el aspecto de la vida colocando el crespón del pensamiento indeciso (1899: 301).

Esta indecisión del pensamiento es lo que posibilita vacilar ante lo recibido, lo aprendido, lo completo, lo perfecto de más arriba. Es lo que agrieta el sentido recto, mostrándonos que también es metafórico. Y esto muestra por qué el lenguaje de Nietzsche se esfuerza por mantenerse poético: para producir, incluso sobre lo que él mismo afirma, esta oscilación.

Ahora bien, hay un aspecto, que aparece varias veces en los fragmentos, en el que Nietzsche y sus editores insisten y, por ello, vale la pena citar de manera amplia un fragmento más:

Creencia en la inspiración. Los artistas tienen interés en que se crea en las intuiciones repentinas, en las pretendidas inspiraciones; como si la idea de la obra de arte, del poema, el pensamiento fundamental de una filosofía cayera del cielo cual rayo de gracia. En realidad, la imaginación del buen artista o pensador produce constantemente algo bueno, mediocre o malo, pero en juicios extremadamente aguzados, ejercitado, 
rechaza, elige, junta; así es como se observa hoy por los apuntes de Beethoven, que compuso poco a poco sus más hermosas melodías y que en cierta manera las seleccionó entre múltiples bocetos. Aquel que discierne menos severamente y se escurre voluntariamente hacia la memoria reproductora, podrá, en ciertas condiciones, volverse un gran improvisador; pero la improvisación estética está a un nivel muy bajo en comparación de las ideas de arte surgidas seriamente y con trabajo. Todos los grandes hombres son grandes trabajadores, infatigables no solamente para inventar, sino también para desechar, tamizar, modificar, arreglar (1899: 302).

Aquí se pone en relieve un tema que le interesa sobremanera a Nietzsche: el del trabajo, y, en particular, el del artista en tanto incesante trabajador. Además, me parece sumamente importante, mostrar de qué manera hay que trabajar el fragmento. Algunas décadas antes de que Walter Benjamin medite sobre el coleccionista, Nietzsche propone aquí al trabajador intelectual, al artista, como coleccionista de sí mismo, como antologador, sobre todo; alguien capaz de elegir y, mediante sus elecciones, de eliminar lo que no vale; pero, además, en el interior variopinto que se presenta, que de hecho es la Revista Moderna, esta es también una encarnación del lector ideal.

Finalmente, de esta primera selección, quiero señalar la insistencia en la conceptualización del arte como posibilidad de evocar a los muertos: "El arte asume accesoriamente la tarea de conservar el ser, de devolver un poco de color a representaciones extinguidas y palidecidas, y teje, así que llena dicha tarea, un lazo alrededor de siglos diversos haciendo volver sus espíritus" (301). Esta idea suplementa e ilumina la índole de ese trabajo antológico: el archivo del poeta o del filósofo no es solamente el de su producción original, sino que comprende toda su biblioteca, el legado completo de la humanidad siempre y cuando le logre "devolver un poco de color" o sea volverlo presencia.Tal posibilidad resulta especialmente importante cuando se lee a la luz del esclarecedor comentario de Luis Miguel Aguilar, para quien el modernismo

seguirá incluyendo el pasado y el futuro, se pondrá delante de la vanguardia y atrás de los románticos, se adaptará a todos los tiempos posibles de la literatura mientras siga funcionando su lección sin lección, su actitud plenamente moderna: en poesía todo es $\tan$ actual y tan viejo, tan local y universal como se quiera; los textos y los autores de distintas partes y tiempos se siguen diciendo y sugiriendo poemas. La poesía moderna es una conversación global e interminable, incluyente y, por lo mismo, nunca concluyente; y al ser el primero que invitó a ella el modernismo garantizó la imposibilidad de antagonizar con él, hacia el futuro, o de hacerlo antagónico, hacia el pasado, bajo pena de acabar con la conversación, de empobrecerla o querer monopolizarla (2001: 139).

Con lo anterior, espero mostrar que la selección que se presenta en la Revista Moderna es un espejo de la poética de sus autores (y editores) modernistas; en otros términos, Nietzsche es bienvenido en la medida en que ayuda a la formación y también al análisis de un ethos modernista.

En la portada de la Revista Moderna de la segunda quincena de enero de 1900, aparece un excelente dibujo de Julio Ruelas:

La imagen lleva a una breve biografía del "filósofo y educador moderno Federico Nietzsche" y, más importante, a la promesa de "consagrar al gran Nietzsche en las columnas de la revista un estudio en toda forma, pues el ilustre educador moderno, padre de una nueva cultura, merece mucho más que estas líneas simplemente informativas" (S. A., 1900: 18). Promesa que, como se verá en los siguientes apartados, la publicación cumple ampliamente. Asimismo, en este número de la revista aparece otra amplia selección de Humano, demasiado humano, que continúa la anterior, incluyendo este importante fragmento: "a veces la exposición incompleta... de un pensamiento, 
de una filosofía entera, es más eficaz que la explicación completa" (1900: 23). Una vez más, una reflexión de su quehacer como filósofo, pero que también ilumina cómo debemos activar la Revista Moderna, en tanto colección permanente de fragmentos que, acaso, nos permiten habitar y entender mejor el ethos modernista que cualquiera de los libros que más tarde escribieron los autores que allí publicaron.

\section{Nietzsche en la Revista Moderna: Lichtemberger}

Unos meses después, la promesa de dedicar más espacio a un estudio de Nietzsche se materializa. En el número del 15 de abril de 1900, se incluye "La literatura de Nietzsche", un largo ensayo firmado por Enrique Lichtemberger. 5 El texto parte del lugar común, lo que llama "la leyenda de Nietzsche", que define como la "imagen mental de lo que flota en el espíritu de los contemporáneos". Tal imagen mental es, en un primer momento (recordemos que el muy célebre episodio de Turín, que marca su hundimiento definitivo en la locura, sucede en enero de 1889), la de "un hermoso monstruo, infinitamente alejado de la medianía humana; ateo intransigente...individualista recalcitrante cuando el socialismo está de moda". Sin embargo, señala Lichtemberger, "las obras publicadas en estos últimos años tienden a humanizar la figura de Nietzsche, a mostrarnos un Nietzsche mucho más vecino nuestro" (1900: 116; todos los subrayados en el original).

Corresponde a la lectura inicial un individuo carente de compasión, desentendido de la moral, para quien la crueldad es una obligación. La segunda, muestra la posibilidad paradójica de que, tras esta caricatura simplona, nos espere un "egotista por altruismo", acerca del cual señala, en primer lugar: "No hay que creer que el egoísmo sea para [Nietzsche] una regla de conducta buena para todos los hombres", juicio que justifica, acertadamente, con una cita de El crepúsculo de los ídolos:

El egoísmo... vale filosóficamente hablando, lo que vale quien lo practica... Porque el ser particular, el individuo, como se lo imaginaban hasta hoy la gente sensata y sencilla, solo es una ilusión, no es nada por sí mismo, no es un átomo ni un anillo de la cadena, ni un resultado del heredismo y del pasado muerto; es toda la línea Hombre, una y entera, hasta él (117).

Esto tiene como consecuencia, para Lichtemberger, que:

en la mayor parte de los casos Nietzsche está de acuerdo con los altruistas en condenar el egoísmo... sencillamente porque la individualidad de la mayoría de los hombres tiene un valor muy pequeño, para que su conservación tenga seria importancia desde el punto de vista general (117).

Esto es, en otras palabras: "Para Nietzsche... los hombres, en su mayoría, lejos de ser fines por símismos, solo deben considerarse como medios y que deben por consiguiente seguir la moral altruista" (117).

Ya en este primer artículo queda claro que, de las dos recepciones iniciales de Nietzsche en español, la Revista Moderna elegirá la del "aristócrata", dejando de lado la del "anarquista".Estos términos, que se repiten con frecuencia en los primeros críticos del pensador, quieren decir respectivamente, como se ha visto en la cita que reproduce Lichtembeger: un pensador que propone una nueva moral para unos pocos, y no la destrucción completa del orden social.Para comprender mejor la manera en que resuena este tipo de lectura en el contexto mexicano, es necesario salir un momento del interior que propone la revista y asomarse al ya para entonces hegemónico "fondo común de ideas", que había creado desde 1867 el esfuerzo positivista.
5. Sobre Henri Lichtemberger (1864-1941) señala Sobejano que publica en 1898 "en la Biblioteca Alcan, el librito [...] La philosophie de Nietzsche, primera exposición lograda de sus ideas. Anunciado ya en enero de 1898 en la Revista Contemporánea, pronto había de difundirse su lectura entre los intelectuales españoles.Los principales representantes del "98" concuerdan que fue la nítida y mesurada síntesis de Lichtemberger la que les proporcionó su primer contacto fecundo con la obra de Nietzsche" (1967: 50-51). En México, la recepción es igualmente temprana, ya en el suplemento $E I$ Mundo llustrado aparece comentado el 27 de marzo de 1898 (239-240). 
6. Sobre Macedo (1856-1929), quien dedicó buena parte de su vida a las cárceles, fue uno de los fundadores de la Unión Liberal, mejor conocida como el Partido de los Científicos y, más tarde, tras el triunfo maderista, a la Escuela Libre de Derecho.Existe una útil biografía breve en [http://historico. juridicas.unam.mx/publica/rev/ hisder/cont/13/cnt/cnt6.htm\#P13]. Su hermano, Pablo Macedo, participó en la Revista Moderna.
7. Pierre Lasserre (1867-1930) escribió dos docenas de libros, y llegó a ser director de la École de Hautes Études. Traductor de Goethe, ya en 1900 había publicado La morale de Nietzsche (1897), que se reeditó en 1903, y en 1905 dio a la imprenta Nietzsche et la musique. En España contó entre sus lectores a Azorín.

8. Jules de Gaultier (1858-1942) es conocido, sobre todo, por proponer el término bovarismo, en 1892. Su lectura de Nietzche comienza con De Kant a Nietzsche de 1900 (por cierto reeditado en 2007 por las Éd. du Sandre), pero no se detiene ahí, todavía en 1926 publica su Nietzsche.

9. Crítico conservador, Lucien Moreau (1875-1932), como Lasserre, forma parte del círculo de L'Action française que concentra a los antidreyfussianos. La mayor parte de lo que escribió apareció en las publicaciones de esa asociación.
Casi de manera simultánea al libro de Lichtemberger, Miguel S. Macedo, uno de los discípulos dilectos de Gabino Barreda, ${ }^{6}$ publica el discurso "La criminalidad en México". Desde el inicio mismo de su alocución, Macedo señala la simultaneidad paradójica del aparatoso índice de asesinatos en la Ciudad de México y la seguridad con la que la viven las clases medias y altas, sin limitar su "extraordinaria libertad de acción en la vida social" (1897: 5). Explica, asimismo, que los dos hechos no se excluyen, debido a que "los homicidios, y en general, los delitos de sangre son cometidos casi en la totalidad de los casos por individuos de la clase baja contra individuos de la propia clase, encerrándose dentro de las capas inferiores de la sociedad como dentro de un recinto que apenas si pueden franquear" (6). Este texto muestra en qué medida Macedo sigue profundamente convencido del abismo que separa a "los superiores y de los inferiores", como los había denominado en el ensayo que presentó dos décadas atrás en los Anales de la Asociación Metodófila, presidida por su maestro Barreda, quien, recordemos, murió en 1881. Ya en ese ensayo exigía "el respeto y la veneración de los inferiores a los superiores" (citado en Zea, 2014: 167).Lo que quiero destacar con este ejemplo es cómo se entendía en el México de 1900 el concepto de aristocracia: los superiores no eran los mejores por sus cualidades, sino por el lugar que ocupaban en la distribución de poder político, encabezado por Porfirio Díaz; dicho de otro modo: los meritorios han sido ya premiados; los mejores son además poderosos y ricos; su labor es mantener ese orden que les permite serlo.

\section{Nietzsche en la Revista Moderna: Lasserre y Gaultier}

El siguiente artículo sobre Nietzsche en la Revista Moderna aparece el 1 de mayo de 1900. "Nietzsche y la literatura francesa", del conservador Pierre Lasserre, ${ }^{7}$ el cual, tras saludar velozmente tanto el libro de Lichtemberger como las traducciones de Henri Albert y más adelante a Georg Brandes, afirma que "la causa cierta del éxito reservado a Nietzsche en Francia [es] su estilo", que contrasta "entre las mil formas de escribir mal" con esa que produce "lo difuso, lo muelle, lo pesado, con esa lentitud germánica formada tanto de conciencia intelectual como de pereza muscular" (1900: 131).

Este artículo, que lograría la trivialidad de hacer de Nietzsche no solo un lector admirado de la literatura francesa, sino un autor francés (mediante la misma operación colonialista con la que incorporan a Borges a esa pléyade algunas décadas después) revela, empero, un aspecto importante. Como elogio máximo a la escritura de Nietzsche, Lasserre dice que "causaría curiosidad a un aristócrata muy inteligente, a un hombre de entera libertad de espíritu y de supremo gusto que viviese en una sociedad muy cuidada por la policía en época de paz pública" (132). La elaboración de este lector ideal muestra un apego a cierta imagen de la aristocracia, relacionada más con su idealización retrospectivamente colocada en algún momento del Ancien Régime que con lo que Nietzsche esboza desde diferentes lugares de su obra. Finalmente, anuncia la importancia del libro De Kant a Nietzsche de Jules de Gaultier, ${ }^{8}$ del cual aparece una larga reseña en la revista, dividida en dos partes, que se incluye en los números de la primera y la segunda quincena de agosto de 1900, poco tiempo antes de la muerte de Nietzsche.

Tal ensayo, firmado por Lucien Moreau, ${ }^{9}$ como consecuencia de la profesionalización del discurso filosófico y de su difusión general, evidencia la "lentitud germánica" de la que se queja Lasserre. En una nuez, la operación crítica que el libro reseñado propone es bien conocida: culpar a un filósofo de la restauración de la metafísica, para otorgarle a otro el mérito de su, ahora sí, definitiva demolición. En este caso, el Kant de la primera Crítica es el culpable y, naturalmente, Nietzsche el héroe (de modo 
semejante al que, a partir del final de la década de los treinta, Heidegger tachará a Nietzsche de metafísico, asumiendo él mismo el papel de pensador definitivo de la postmetafísica). ${ }^{10}$ No es poco importante apuntar que en esa demolición de los pensadores precedentes, Gaultier

encuentra todavía vestigios teológicos hasta en los positivistas como Augusto Comte (la religión de la humanidad); como Littré (la tendencia a la identidad), como Herbert Spencer (la moral de la selección, que como la filosofía dogmática, descansa en la ilusión finalista e implica: 10 que la vida tiene un fin; 20 que ese fin nos es cognoscible). Carlyle mismo, confiesa que el hombre ha creado, no recibido la moral y que el primer origen de la moral, puesto que no tiene bien en sí, solo puede ser un hecho de dominación (1900: 239).

\section{La sobrevida de Nietzsche}

¿En qué medida los lectores de la Revista Moderna tomaron nota de cómo el positivismo también resultaba culpable de los mismos pecados que los filósofos a los que pretendía sobreseer? ¿En qué medida se dieron cuenta de que la verdadera aristocracia, en los términos de trabajo artístico, de exigencia y selección que proponía Nietzsche y no de mera ocupación de puestos de poder, estaba cerca de lo que ellos mismos hacían en tanto autores y editores? Acaso la respuesta solo llegue con los pensadores que, como José Vasconcelos, ajustan cuentas con el positivismo una vez que la Revolución lo ha exterminado.

Nietzsche podría haber sido la cifra de este corte, pero queda como su preludio. Después del período estudiado, las apariciones de Nietzsche en la Revista Moderna no son ya como autor de sus propios textos o como objeto de explicaciones que no alcanzan a sondar el riesgo de sus textos, sino como una autoridad que acompaña a los autores modernistas sin desviarlos de su sensibilidad. No hay espacio aquí sino para un solo ejemplo: en el número de la primera quincena de octubre de 1902, aparece el capítulo XXXII, dedicado a Múnich y a Wagner, de Eléxodo y las flores del camino, la encantadora crónica de viaje de Amado Nervo. ${ }^{11}$ En la capital de Baviera, en uno de sus momentos de mayor felicidad, el joven poeta mexicano asiste a la tetralogía $E l$ oro del Rin. Como buen intelectual periférico, le asusta pasar por aficionado rastacueros, así que asiste pertrechado: lleva el libreto de la ópera, lleva a D’Annunzio y, más importante para nosotros,

a Federico Nietzsche [... E]l ilustre muerto me lleva de la mano, como en otro tiempo el florentino con su Virgilio, entro a ese abismo oceánico de armonía sin riberas [...] Para que un acontecimiento sea grande - dice Nietzsche en su libro sobre Bayreuth-, dos condiciones deben encontrarse reunidas: la grandeza de sentimiento de aquellos que lo realizan y la grandeza de sentimiento en aquellos que son sus testigos. Por esto, ante la aproximación de todo acontecimiento importante, cada uno se pregunta con inquietud si aquellos que van a asistir son realmente dignos... (1902: 291)

Para su felicidad, el público de Munich es cultísimo, intimidante. Pero lo que interesa subrayar aquí es cómo Nietzsche es, precisamente, su Virgilio, no solo en los aspectos técnicos de la música, tema del que sabe y mucho, sino en cuanto a la manera de saber si un acontecimiento es "grande"; esto es, digno del aristócrata del gusto. Más aún: trae un libro que no está compuesto de fragmentos tan breves como los que se privilegiaron otrora en la Revista Moderna uno de los libros que marcará, como demuestra Ugalde en su importante artículo, a la generación siguiente.
10. Para una periodización de esta lectura, véase el útil artículo de Carman.

11. He releído a profundidad este libro de Nervo en mi texto "Pale Theory" (2018a). 
12. Ver el artículo de Susana Zanetti sobre el número inicial (1999).

13. Sobre las primeras publicaciones en México se puede consultar mi "(Pobre) Baudelaire en México” (2018b).
14. Al igual que "agnóstico", "nihilista" es un neologismo acuñado en el siglo XIX por Turguenev, quien lo usa en Padres e hijos, novela que sólo se traduce al español en 1910, aunque, en la Revista Moderna se publican algunos textos suyos más breves. En el caso de la recepción española el término se usa con cierta vaguedad, como sustituto de "anarquista" en la ola de recepción anterior, privilegiando la parte iconoclasta de su pensamiento genealógico.

15. Como nos recuerda Alejandro Sánchez Lopera en su Nihilismo y verdad: Nietzsche en América Latina (2017: 4), libro que pasa casi completamente por alto la recepción inicial durante el modernismo.

\section{Conclusión}

La Revista Moderna fue un interior que reflejó estéticamente el ethos modernista, que sirvió como refugio contra la censura oficial, ${ }^{12}$ y fue la casa que protegía de los límites convencionales. En ella convivieron Nervo, Tablada, Ciro B. Ceballos, Francisco M. Olaguíbel, Darío, Lugones y Silva, que dominaron el espacio de sus páginas, pero dejando espacio para Baudelaire, quien, después de una difícil infancia, ${ }^{13}$ se traduce mucho aquí, y para Mallarmé, Tolstói, y Gide que alcanzan a asomarse. Es en esta constelación en la que Nietzsche encuentra hospitalidad. Representa prácticamente el único filósofo convocado a la revista, y, como se vio más arriba, le publican textos en los que rehúye el sistema o, mejor, la forma recibida que hacía presuponer la sistematicidad. Además, estos fragmentos le permiten desmontar, desconstruir, según se dijo, esas formas "perfectas". Vale la pena recordar aquí que los pocos libros que aparecen serializados - En el país del sol de Tablada, y El éxodo y las flores del camino de Nervo, ya mencionado- están lejos de la novela de folletín, y responden en sí mismos a estéticas de la estampa, del silencio, del fragmento.

En este momento, en el mundo de habla hispana, se dan dos recepciones de Nietzsche, la que lo llama nihilista ${ }^{14}$ y la que lo prefiere aristócrata. A estas, como se ve ya en el artículo sobre el libro de Gaultier, también se agrega la de antimetafísico, que sirve para acusar al positivismo de su motor teológico. En todos los casos el campo semántico es tan amplio como vago, pero por eso estimulante: la posibilidad de una aristocracia que no sea la de la élite de Díaz y los Científicos, así como la voluntad de poder que, finalmente, marcará el ocaso de toda esta época con los estallidos sucesivos de la Revolución, que establecerá una importancia retrospectiva de estas publicaciones iniciales y la necesidad de un nuevo Nietzsche: acaso ese que se dibuja con Mariátegui, el cual abre sus Siete ensayos de interpretación de la realidad peruana precisamente con una cita de El viajero y su sombra. ${ }^{15}$ Un Nietzsche que clama, justo, por una genealogía. 


\section{Q Bibliografía}

》 Aguilar, L. M. (2001). La democracia de los muertos: ensayo sobre poesía mexicana 1800-1921. México, Cal y Arena.

"Beckman, E. (2013). Capital Fictions: The Literature of Latin America's Export Age. Minnapolis, U. of Minnesota.

»Carman, T. (2016) “Heidegger's two Nietzsches”. En [http://blogs.law.columbia.edu/nietzsche1313/heideggers-two-nietzsches/].

»Darío, R. (2016), “Los raros. Filósofos «finiseculares» Nietzsche-Multatuli”. En Zama.Extraordinario: Rubén Darío, pp. 267-270.

"Echeverría, B. (2002). La clave barroca de América Latina. México, UNAM. [http://www.bolivare.unam.mx/ensayos/La\%2oclave\%2obarroca\%20en\%20 America\%2oLatina.pdf].

" Gutiérrez Girardot, R. (1994). Nietzsche y la filología clásica. Málaga, Universidad de Málaga.

» Gutiérrez Girardot, R. (2004). Modernismo: supuestos históricos y culturales. Bogotá, FCE.

» Kofman, S. (1993). Nietzsche and Metaphor. Trans. Duncan Large. Stanford, Stanford University Press.

»Lasserre, P. (1900). “Nietzsche y la literatura francesa”. En Revista Moderna, año 3, núm. 9, $1^{\underline{a}}$ quincena de mayo, pp. 131-135.

»Macedo, M. S. (1897). La criminalidad en México. México, Of. Tip. de la Sría. de Fomento. [https://babel.hathitrust.org/cgi/pt?id=hvd.32044057475568;view=1u $\mathrm{p} ; \mathrm{seq}=9 ;$ size $=75]$

» Mejías-López, A. (2010). The Inverted Conquest: The Myth of Modernity and the Transatlantic Onset of Modernism. Nashville, Vanderbilt University Press.

» Moreay, L. (1900). “De Kant a Nietzsche, por Julio de Gaultier”. En Revista Moderna, año 3, núms. 15-16, $1^{\underline{a}}$ y $2^{\underline{a}}$ quincenas de agosto, pp. 237-240, 249-251.

"Nervo, A. (1902). “XXXII. Múnich. Wagner”. En Revista Moderna, año 5, núm. 19, $1^{\underline{a}}$ quincena de octubre, pp. 290-291.

» Nietzsche, F. (1899). “Humano, demasiado humano”. En Revista Moderna, año 2, núm. 10, octubre, pp. 300-304.

» Nietzsche, F. (1900). “Humano, demasiado humano”. En Revista Moderna, año 3, núm. 2, $2^{\mathrm{a}}$ quincena de enero, pp. 21-27.

»Pereda, C. y Leyva, G. (2001). "La recepción de la filosofía alemna en México". En Bierber, L. (coord.). Las relaciones germano mexicanas. Desde la época de los hermanos Humboldt hasta el presente. El Colegio de México-DAAD-UNAM, pp. 215-264.

"Pineda Franco, A. (2016). “Mexican Modernismo”. En Ignacio Sánchez Prado, Anna Nogar y José Ramón Ruisánchez Serra. A History of Mexican Literature. New York, Cambridge University Press, pp. 218-229.

»Ruisánchez Serra, J. R. (2018a). "Pale Theory. Amado Nervo, Theorizing the Absential”. In Ignacio Sánchez Prado (ed.). Mexican Literature in Theory. New York, 
Bloomsbury, pp. 55-74.

»Ruisánchez Serra, J. R. (2018b). “(Pobre) Baudelaire en México”. En Saga Revista de Letras, núm. 8. [http://sagarevistadeletras.com.ar/archivos/8.RuiSanchez-1.pdf]

» S. A. (1900). “Federico Nietzsche”. En Revista Moderna, año 2, núm. 2, enero, p. 18.

»Sánchez Lopera, A. (2017). Nihilismo y verdad: Nietzsche en América Latina. Peter Lang.

"Schulman, I. (2002). El proyecto inconcluso: la vigencia del modernismo. México, Siglo XXI.

»Sobejano, G. (1967) Nietzsche en España. Madrid, Gredos.

»Ugalde Quintana, S. (2019). “Alfonso Reyes lee a Nietzsche: cultura clásica y ethos agonista”. En Nueva Revista de Filología Hispánica LXVII-1, pp 131-153.

»Zanetti, S. (1999). “El modernismo de la Revista Moderna de México". En Taller de Letras, núm. 27, noviembre, pp. 181-187.

»Zea, L. (2014). El positivismo en México: nacimiento, apogeo, decadencia. México, FCE. 